We wish to thank Profs. A. Haddow and J. F. Danielli for their interest and encouragement. We are indebted to Sister Carmela Hayes for a culture of $A$. discoides, to Dr. Charity Waymouth for the tissue cultures, and to Mr. F. S. Speed and Mr. M. S. C. Birbeck for the cinematography. The work was carried out during the tenure by one of the authors (R. J. G.) of a grant from the Forsyth Bequest of the Royal Society, and was supported by grants to the Royal Cancer Hospital from the British Empire Cancer Campaign, the Jane Coffin Childs Fund for Medical Research, the Anna Fuller Fund, and the Division of Research grants of the U.S. Public Health Service.

1 De Bruyn, P. P. H., Quart. Rev. Biol., 22,1 (1947).

Holtfreter, J., Proc. 6th Internat. Congr. Exp. Cytol., Stockholm, 497 (1947).'

- Elkes, J. J., Frazer, A. C., Schulman, J. H., and Stewart, H. C., Proc. RMy. Soc., A, 184, 102 (1945). Langmuir, I., and Schaeffer, . J., Chem. Rev., 24, 181 (1939), Langmuir, I., and Waugh, . F., Amer. Chem. Soc., 62, 2771 (1940). Neurath, H., Green, , 'Them. Rev.' bility of Natua

- Oster, G., and Grimsson, H., Archiv. Biochem., 24, 119 (1949).

Hopkins, D. L., Biodynamica, 2,1 (1938). Carrel, A., and Ebeilng, A. H., J. Ezp. Med., 44, 261 (1926).

"Szent-Gyorgi, A..' "Chemistry of Muscular Contraction" (Acad. Press Inc., N.Y., 1947).

Calkin, G., and Summers, F., "Protozoa in Biological Research", 18 (Columbia Univ. Press, ì.Y., 1941).

- Clark, A. M., Aust. J. Exp. Biol. Med. Sci., 20, 241 (1942).

- Commandon, J., and de Fonbrune, P., C.R. Soc. Biol., 130, 740, 744 (1939).

${ }^{10}$ Iorch, I. J., and Danielli, J. F., Nature, 166, 329 (1950).

11 Schaeffer, A. A., Arch. f. Protistenk., 37, 204 (1917).

${ }^{13}$ Astbury, W. T., Nature, 167, 121 (1946).

\section{PRESENTATION OF TECHNICAL INFORMATION}

T

HE discussion at Birmingham, on September I, arranged jointly by Sections A (Mathematics and Physics), G (Engineering) and J (Psychology) of the British Association, on the presentation of technical information attracted an audience in which other sections, notably chemistry, were also well represented. Prof. R. O. Kapp, who opened the discussion, pointed out that a large and growing portion of the time of a scientific worker or engineer is now concerned with the written and spoken word, and the presentation of technical information is no Ionger of subordinate importance but dominates many of our activities. This is an inevitable consequence of the development of our delicately balanced civilization, which depends more and more on collaboration within an everwidening circle. This collaboration, he said, can only be achieved with the help of an interchange of information, much of which is technical, and the written and spoken word have now become important tools with which scientific men and engineers have to work. From this point of view, Prof. Kapp developed his plea for more care and thought in the art of exposition, both to avoid the waste of time of the reader, and to avoid the possibility of misunderstanding or misinterpretation leading to wrong action. Equally, he observed, if a report is not adapted to its purpose, confusing or difficult to follow, ambiguous, or requiring excessive time for perusal, it may easily lead to the report being ignored, with the result that some desirable action is not taken. Reports, he insisted, are an essential part of the machinery of an organisation, and the efficient working of an organi- sation depends on their quality as much as it does on the quality of the tangible machines.

Prof. Kapp suggested that in our failure to appreciate the importance of the proper technique in the presentation of technical information, we have lapsed from early standards. The writings of eighteenthcentury scientific men show many examples of good exposition, and it was only as the nineteenth century advanced that the increasing preoccupation of scientific men with their own specialized field made most of them tend to become less aware of other people. Prof. Kapp did not pursue the question whether the art of technical exposition could fairly claim to be recognized as an intellectual discipline; but he urged that we should at least study the technique in all its aspects and attempt to perfect and to teach it. Whether we are concerned with scientific books and papers to learned societies, with the spoken word such as the lecture, with the technical report, with that voluminous but valuable technical literature, often unjustly disparaged, which every manufacturer has to issue to ensure that his customers make proper use of his products, or with the spoken word in conference and committee, full regard must be had to the psychological factor if exposition is to be appropriate and effective.

This need for the good expositor to be vividly aware of other people was also illustrated by Prof. Kapp in reference to typography, and the choice of the most appropriate method for conveying technical information pictorially; but he pointed out that if illustrative material is not good, or if it is not used on a suitable occasion or on a suitable subject, it is ineffective, and by wasting time and diverting attention from the subject under discussion may even be misleading. While linguistics is the aspect of exposition most commonly referred to, Prof. Kapp believes that mastery of the English language is less important than either logic or awareness of the person addressed. The expositor who would express himself with precision must think clearly not only about the theme under discussion but also about the person to whom the information is being conveyed. The art of exposition demands more than anything else an understanding of the work done by the person to whom technical information is being presented.

This factor did not receive much discussion in the following papers, though it was well illustrated in Mr. L. Bainbridge-Bell's lively exposition of the need for clearer circuit diagrams. Those who were not electrical engineers followed his handling of a highly technical theme with obvious enjoyment and understanding, and his question to the visitor who remarked that it is nice sometimes to puzzle over a diagram, "When you ask your boss for a rise, do you put it in as an acrostic?", well illustrates the practical character of his suggestions and principles for clearer presentation.

Miss M. D. Vernon's paper, giving a psychologist's view, said less than might have been expected about that aspect. It presented the results of an inquiry into the effectiveness of the use of graphical data, which emphasized the hiatus between the ability of the scientific worker and that of school children and the general public to understand numerical data presented to them in the form of diagrams, graphs or tables of figures. In general, Miss Vernon's inquiry suggested that the reader will not profit much from the inclusion of such data with a written text unless he or she has had sufficient training and experience in the use of such graphical forms, and that they 
must be simple and must not give information differing in any way from that presented in the text. Furthermore, the general argument or thesis must be clearly stated in the text, because the reader will be unlikely to work it out independently from the graphical and numerical data alone.

Miss Vernon's paper thus supported Prof. Kapp's plea for further study on the value of particular methods of illustrative material. Mr. Geoffrey Parr's paper on the relations between the technical author and his publisher was concerned in part with ways in which the average delay of four to six months in the publication of articles and fifteen to twenty months in the publication of books could be minimized by greater attention to details on the part of authors. In the average book of 80,000 words, the actual text or manuscript forms only $55-75$ per cent of the whole book. Drawings and photographs may occupy 1535 per cent, and preliminary matter, bibliographies, glossaries, and the index account for the remainder. The illustrations and the comparatively small remainder are the usual causes of delay in production, and Mr. Parr gave a check list of details liable to be overlooked which the author should verify as com. pleted before submitting a manuscript.

Such a check list would include: all text pages numbered consecutively; figures and photographs numbered consecutively; suitable deseriptions for each figure; permission to reproduce each borrowed figure; acknowledgments in preface; table of contents; list of plates (if not in text-matter); preface; foreword; bibliography checked and complete; references in text complete; references back in text made accurately; appendixes, if any; glossary; list of symbols (and examination of text to see that all symbols agree with list); and mathematics clearly set out. If all these are checked and complete, the delay in production caused by referring back to the author will be considerably lessened. Mr. Parr said that, in his experience, many of these items are regularly overlooked, and that among six hundred manuscripts read and checked during the past ten years, only five authors had submitted manuscripts in such a form that they could be sent to the printer without delay or query. He said that it is rare to receive a manuscript which does not involve lengthy correspondence and waiting time while the missing information is produced.

In the remaining paper, Mr. F. M. Colebrook.dealt with the special features of the writing of scientific and technical papers which arise when the author is a member of the paid staff of a scientific organisation
- more particularly of a national, or at least not a commercial, organisation. Mr. Colebrook drew mainly on his own experience in the National Physical Laboratory, and urged that the first distinctive feature is that the writing of papers by the staff of such organisations is, in general, a public duty, since such papers are sometimes the main return to the public for the public money spent. It followed that it is an obligation on the senior officers of such organisations to see that the papers are written, and are written well. The practical problem is very often to persuade the reluctant authors, but besides this it is necessary for the organisation to assist and advise its potential authors. This is bound up with the second distinctive feature, that the good name and reputation of the organisation as a whole are involved in the papers that are written by its individual members. Mr. Colebrook recognized that this gave the organisation the right, if not the obligation, to foster and insist on a high standard of presentation and also the right to control publication within certain limits. This he regarded as a proper and useful discipline rather than any real infringement of freedom of expression; but he thought that the balance of argument is heavily against anonymity, and that any departure from the principle that the names appearing on papers should be those of the real authors is a breach of professional ethics. Mr. Colebrook took the view that the reading of the paper in manuscript by one or more colleagues is an aid to the maintenance of high standards of presentation, and that organisations could also assist the early and effective dissemination of information.

Apart from these points, however, Mr. Colebrook's paper, like the other papers and contributions to the discussion, was stronger at diagnosis than in sugges. tions for action. Prof. Kapp, indeed, suggested that study of the factors on which receptivity depends, the laws which govern the association of ideas and the way memory works, would be useful, as well as the investigation of the criteria for distinguishing between good and bad methods of pictorial presentation; but no one went nearer to the root of the immediate trouble than the overseas student who pleaded that some systematic instruction in the presentation of reports and scientific papers should be given in the universities. With that and effective teaching of English usage and composition in the schools, there should be little need for a periodical on the subject. or for further additions to a reasonably adequate literature, at least so far as the linguistic aspect is concerned.

\section{NEWS and VIEWS}

\section{New South Wales University of Technology}

DURING the past year, considerable attention has been paid to the encouragement and organisation of research work within the New South Wales University of Technology. Facilities for carrying out investigations have been established, including the appointment of research workers and technical officers with sufficient time free from teaching commitments to enable them to assist the professors and lecturing staff in designing equipment, in setting up apparatus, in carrying out tests and ensuring con- tinuity of work. In addition to the generous Nuffield grant of $£ 25,000$ for the Nuffield research professorship in mechanical engineering, the work of the University has been given further tangible recognition by the Commonwealth Universities Commission, which has allocated $£ 10,000$ for carrying out research work in the University in 1950 , and a similar amount for 1951. The Joint Coal Board has given $£ 11,000$ for research into mining problems. Projects being undertaken in the fields of applied chemistry and chemical engineering are prominent in the list, and in certain cases are being carried out in conjunction 